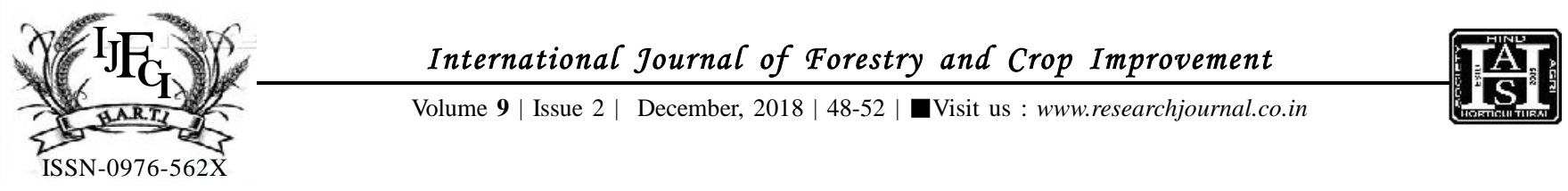

RESEARCH ARTICLE

DOI: $10.15740 / \mathrm{HAS} / \mathrm{IJFCI} / 9.2 / 48-52$

\title{
Evaluation of selected fungicides against false smut disease of rice caused by Ustilaginoidea virens
}

\author{
Ashraf Ali Khan and A.K. Singh
}

\begin{abstract}
The present study was conducted to find out suitable management options against this disease, a field trial was carried out using six fungicides viz., Coper hydrocide 77\% WP @ (0.10\%), Trifloxistrobin + Tebuconazole 75WG $(0.04 \%)$, Propaconazole 25 EC (0.10\%), Kresoxim methyl $44.3 \mathrm{SC}(0.04 \%)$, Copper oxychloride (0.25\%) and Carbendazim $50 \mathrm{WP}(0.10 \%)$. There was significant difference among the treatments in false smut disease severity and yield. The best results was obtained in treatment of spraying rice field byTrifloxystrobin + Tebuconazole $75 \mathrm{WG}$ with maximum reduction in disease severity (68.6) and disease incidence (48.1), which gave least disease severity (1.6\%) and disease incidence (8.6), it was at par with the treatment propiconazole $25 \mathrm{EC}$ (2.6\%), followed Kresoxim Methyl $44.3 \mathrm{SC}(2.9)$. However Carbendazim 50 per cent WP treated plots showed highest (4.0\%) disease severity and 15.8 per cent disease incidence. In terms of grain yield, the treatment with Trifloxystrobin + Tebuconazole 75WG gave maximum increase (23.6\%) in yield and 15.2 per cent increase in 1000 grain weight, it is followed by Propaconazole $25 \mathrm{EC}$ with 21.6 per cent increase in grain yield and 10.6 per cent increase in 1000 grain weight. The least percentage increase of grains yield (11.13\%) and 1000 grain weight (4.0\%) was recorded in carbendazim sprayed plots.
\end{abstract}

KEY WORDS : False smut, Management, Fungicides, Ustilaginoidea viren

HOW TO CITE THIS ARTICLE : Khan, Ashraf Ali and Singh, A.K. (2018). Evaluation of selected fungicides against false smut disease of rice caused by Ustilaginoidea virens. Internat. J. Forestry \& Crop Improv., 9 (2) : 48-52, DOI: 10.15740/HAS/IJFCI/9.2/48-52. Copyright@ 2018: Hind Agri-Horticultural Society.

Article Chronical : Received : 24.10.2018; Revised : 15.11.2018; Accepted : 26.11.2018

MEMBERS OF RESEARCH FORUM

Address of the Correspondence : Ashraf Ali Khan, Krishi Vigyan Kendra, Aligarh (U.P.) India

Email: aali_khan@ rediffmail.com

Address of the Coopted Authors : A.K. Singh, Directorate of Extension, C.S.A. University of Agricultural and Technology, Kanpur (U.P.) India 